\title{
Urological consequences following renal transplantation: a review of the literature
}

\author{
Anna Palazzetti, Marco Oderda, Ettore Dalmasso, Marco Falcone, Andrea Bosio, Omid Sedigh, Bruno Frea, Paolo Gontero \\ Department of Urology, University of Turin, Città della Salute e della Scienza Hospital, Turin - Italy
}

\begin{abstract}
Renal transplant (RT) represents the treatment of choice for end-stage renal disease (ESRD) but harbours a wide range of possible complications and therapeutic challenges of urological competence. Dialysis years and clinical medical background of these patients are risk factors for sexual dysfunction and lower urinary tract symptoms (LUTS). On the contrary, RT itself may have a number of possible surgical complications such as ureteral stenosis and urinary leakage, while immunosuppressive treatment is a known risk factor for de-novo malignancies.

The present review describes the main urologic problems of RT patients and their up-to-date treatment options according to the most recently available literature evidences.
\end{abstract}

Keywords: Complications, Kidney, Kidney disease, Renal transplant, Urological consequences

\section{Introduction and objectives}

Renal transplant (RT) is the treatment of choice for endstage renal disease (ESRD), and the best option for patients quality of life. RT patients in the majority of cases have undergone many years of dialysis because of ESRD, with a lot of possible urological consequences mainly in terms of infertility, sexual, and lower urinary tract dysfunction. Furthermore, RT patients need prolonged immunosuppressant treatment, carrying itself a risk of infections and neoplastic diseases (1). Moreover, RT is not free from specific urological complications that might finally lead to allograft nephrectomy (AN). Taking all these things into consideration, a careful urological follow-up is advised for RT patients. The aim of the present review is to focus on the most relevant aspects of urological interest in RT patients, and particularly on surgical urological complications and their possible therapeutic solutions comprising transplant nephrectomy, urological de-novo malignancies, lower urinary tract symptoms (LUTS), graft lithiasis, and andrological dysfunctions.

\section{Evidence acquisition}

A literature search was conducted according to current methodological recommendations for systematic reviews (2).

\section{Accepted: July 3, 2015}

Published online: July 28, 2015

Corresponding author:

Anna Palazzetti, MD

Department of Urology, University of Turin

Città della Salute e della Scienza

Corso Bramante 88-90

10126 Turin, Italy

anna.palazzetti@gmail.com
The search was focused on the following areas of interest concerning RT patients: surgical complications, urologic malignancies, LUTS, graft lithiasis and andrological dysfunctions. The PubMed databases were searched using the following keywords: 'kidney transplant', 'renal transplant', and associated with 'erectile dysfunction', 'male infertility', 'azoospermia', 'surgical complications', 'urological neoplasm', 'graft lithiasis', 'transplant nephrectomy' and 'lower urinary tract symptoms'. All identified articles were examined by the authors, and the most relevant articles were selected according to their level of evidence, as reported by Phyllips et al (2). Further text searches were performed by separately adding the following keywords: 'diagnosis', 'management' and 'therapy'. Evidence synthesis is herein reported.

\section{Evidence synthesis}

\section{Post-RT surgical urological complications}

The most common surgical urological complications include ureteral stricture and urinary leakage.

Ureteral strictures are generally classified as early $(<3$ months from RT) and late-onset (>3 months). The former may be caused by kinking, temporary oedema of the ureteral wall, narrow anastomosis or extrinsic compression by haematoma or lymphocele $(3,4)$. The latter are usually related to bad ureteral vascularisation resulting in ischemia and subsequent fibrosis and three risk factors have been identified: donor age more than 65 years, kidneys with more than two arteries and delayed graft function (5). Another cause of late-onset ureteral stenosis but with different pathogenesis is represented by BK virus (BKV) infection. This DNA virus acts as a pathogen only in immunocompromised population. Urothelial cells are natural reservoirs for $\mathrm{BKV}$ replication and ureteral stenosis associated with this 
virus accounts for $2-6 \%$ of all cases. Histologically, the stenotic tract appears ischaemic and fibrotic, resembling the lack of vascularisation encountered in bad vascular supply cases (6). Ureteral strictures may be treated with an endourologic (usually percutaneous) or a surgical approach. Balloon dilation and temporary ureteral stenting are the most common endourologic procedures. Generally, percutaneous approach is considered as the first option, as it is simpler and has both a diagnostic and therapeutic value (7). In the short term, endourologic procedures have a high success rate (from 73 to $100 \%$ ), dropping to $40-55 \%$ in the longterm due to a high recurrence rate (8-11). In 2005, Juaneda et al identified early obstruction and the presence of previous acute rejection as factors associated with better success rates (7). In the algorithm proposed by Helfand, a stricture less than $3 \mathrm{~cm}$ in length was considered as a good prognostic factor (12). Recently, He et al proposed a new classification on the basis of the entity and nature of the stricture. Specific treatments correspond to different grades of strictures: temporary stent placement for G1 (increased creatinine and hydronephrosis without evidence of significant stricture), balloon dilation or endoscopic incision for G2 (stricture $<1 \mathrm{~cm}$ ), and immediate surgery for $\mathrm{G} 3$ (stricture $>1 \mathrm{~cm}$ ) (13). Ho:YAG laser endoureterotomy of the stenotic tract has a high success rate $(>80 \%)$ in case of strictures less than $0.5-1 \mathrm{~cm}(14,15)$. Surgery provides the highest success rate $(>75 \%)(12,16,17)$. According to algorithms proposed by Helfand and $\mathrm{He}$, surgery might be indicated after failure of endourologic treatment or as immediate treatment in case of late-onset strictures more than $3 \mathrm{~cm}(12,13)$. The feasibility of a so-called extra-anatomic stent has been recently described as a salvage procedure when surgery is not indicated or ineffective (18).

Urinary leakage occurring within 15 days from RT is usually due to anastomosis dehiscence, whereas ureteral necrosis owing to vascular insufficiency is the main cause of later events $(19,20)$. Donor age and delayed graft function have been identified as independent risk factors for ureteral leakage (5). To avoid this complication, a careful preservation of ureteral vascularisation both during organ procurement and transplantation is mandatory (19). The endourologic management consists in temporary ureteral stenting or nephrostomy, even though it is not as effective as in strictures. Specific factors have been related to better treatment outcome, such as the occurrence of leakage more than 3 days after RT and a small entity of leakage, allowing the passage of contrast into the bladder at the first pyelography. According to recent studies, success rate of ureteral stenting for leakage ranges between 36 and 85\% (21-23). In case of failure of endourologic treatment and in proximal or massive leakage, surgery is the only option $(24,25)$.

When surgical intervention is indicated, two options are available to manage leakages or stenosis: ureteral reimplantation or reconstruction with native urinary tract. Ureteral reimplantation is indicated in case of anastomotic or distal defects. The most used surgical techniques reported in literature are Lich-Gregoire, Taguchi, and Politano-Ledbetter reimplantation. Tagichi reimplantation, therefore, is associated with more haematuria episodes, while Lich-Gregoire technique is the preferred one, as it is a relatively easy procedure, it does not require a second cistotomy such as
Politano-Ledbetter reimplantation, and it requires less ureteral length compared with other techniques $(26,27)$. Pike et al described 18 strictures corrected with direct reimplantation (occasionally requiring mobilisation of the urinary bladder) and 19 with reimplantation on a Boari flap, with a graft survival of $72.5 \%$ at 5 years (28). In a large series by Karam et al, reimplantation had no impact on graft survival as compared with non-stenotic grafts (10-year graft survival, 64 vs. $63 \%, p=0.36$ ) (5). Native urinary tract can be used to perform uretero-ureterostomy (UU), pyelo-ureterostomy (PU) and, less frequently, pyelo-pyelostomy (PP), with acceptable success rates (76-100\%) considering that only small series have been reported $(24,29-31)$.

\section{Allograft nephrectomy}

Nowadays, graft failure rates are declining due to an improvement in immnosuppressive regimens. Nevertheless, acute or chronic rejection of allograft still happens and represents an indication to AN. Other indications are represented by vascular complications, including thrombosis, infectious complications and neoplastic diseases (32). AN is considered as early if performed within 12 months from RT and late if performed afterwards (33). Late AN represents a challenging procedure due to the desmoplastic reaction of the graft on chronic rejection that makes it adherent to the abdominal wall. As a consequence, late AN might harbour more perioperative complications than early ones, such as major bleedings and death (32). When performing an AN, two major techniques are possible: intracapsular AN (ICAN) and extracapsular AN (ECAN). ICAN is performed by means of previous skin incision, graft identification, subsequent capsulotomy and finding of the plane between kidney parenchyma and renal capsule that is subsequently developed digitally until identification of the hilum that is closed with a vascular clamp and sutured with a two-line running suture. On the contrary, ECAN considers the complete and precise identification of vascular structures: artery and vein, and ureteral dissection until the bladder anastomosis. Subsequently, the structures are all ligated separately and $\mathrm{AN}$ is performed. As a matter of fact, the main difference between the two techniques is that ICAN leaves more donor tissues inside the recipient than ECAN, this possibly being a cause for allosensitisation and a reduced success of further transplantations. Literature findings on this topic are inhomogeneous. Touma et al in a recent study comparing ICAN with ECAN demonstrated a higher complication rate in the ECAN group in terms of perioperative bleeding and mortality (34). On the contrary, Mazzucchi et al did not find any statistically significant difference between the two techniques (32). Despite that, the only pathology that makes ECAN mandatory is graft neoplasia that forces surgeons to remove the entire graft for oncologic reasons. Independently from kidney neoplasm, further studies are needed to compare the two techniques to establish which is the less morbid.

\section{Urologic de-novo malignancies following $R T$}

RT patients have an increased risk of developing neoplastic diseases (35), mainly due to immunosuppressive 
treatment. This is the main risk factor for both short and long-term neoplasms, even though not every cancer type has the same etiopathogenetic association with immunosuppression (36). Among the mechanisms by which immunosuppressive treatment may favour malignancies are impaired immune surveillance and infections by oncogenic viruses. Irrespective of the causes, malignancy is the third cause of death in RT recipients following cardiovascular diseases and infections.

De-novo cancer is a major complication of RT that causes significant short and long-term mortality. It accounts for $20 \%$ of RT patient deaths every year and $30 \%$ of deaths among RT recipients with a follow-up greater than 20 years (37). According to the main registries on this topic, which are the Cincinnati Transplant Tumor Registry (CTTR), the Nordic Renal Transplant Registry (NRTR) and the Australian and New Zeland Transplant Registry (ANTR), the most frequent de-novo neoplasms following RT are skin cancer and posttransplant lymphoproliferative disease (PTLD). De-novo cancer incidence in patients followedup more than 20 years is between 34 and $50 \%$ and, of these, $75 \%$ are skin cancers (38).

Focusing on urological malignancies, renal cell carcinoma (RCC) is the most frequent neoplasm accounting for almost $31 \%$ of all urologic malignancies and for $3.3 \%$ of post-RT overall malignancies. RCC most frequently arises in native kidneys. A well-known risk factor is represented by developing acquired cystic kidney disease (ACKD), a condition that progressively increases with the duration of chronic kidney disease and time on dialysis. Moreover, data also suggest that an unexpected underlying nephropathy, a uremic state, dialysis time and transplantation itself might have a role in malignant transformation of native kidneys (39). Nine cases have been reported in one of the largest series reported in literature, showing a 15 -fold increased risk of developing RCC compared with general population (40).

According to Penn et al, the majority of kidney cancer is diagnosed early after RT, maybe due to more intense immunosuppression, while graft involvement is a rare event that requires every effort to spare the graft itself. Breda et al recently performed a retrospective study comparing pathologic characteristics of RCC arising in ESRD patients (under dialysis or after transplantation) with general population. Their results highlighted how RCC arising in ESRD patients harbour less aggressive characteristics, being much smaller, lower grade and lower stage tumours, thus leading to a 5 -year cancer-specific survival of $90 \%$ compared with $69 \%$ of general population (41).

When feasible, conservative surgery represents the first choice in this case. There are also a few case reports of graft RCC treated with cryoablation or other minimally invasive techniques (42). Radical nephrectomy is indicated for RCC affecting native kidney irrespectively of its stage and grade. Concerning immunosuppressive regimen, the introduction of mammalian target of Rapamicin (mTOR) inhibitors, because of their well-known anti-proliferative activity, is highly suggested even if not already standardised (43).

As for bladder tumours, the most frequent pathological pattern is transitional cell carcinoma (TCC), with a three-fold risk compared with the general population. Overall incidence of TCC in RT population is $0.4 \%$. The relative risk (RR) of TCC in RT recipients is very high in China, as compared with western countries (RR 14 vs. 2), probably due to the consumption of aristolochic acid and rhubarb, which are known TCC risk factors and are widely used in Chinese traditional medicine (44). Moreover, in the Asian population, there is a trend towards higher incidence of upper urinary tract involvement associated with higher-grade initial presentation in RT patients compared with dialysed ones. Zhang et al, in a single-centre retrospective study, confirm these data but no statistically significant differences in overall and cancer-specific survival are reported from the authors between the two populations (45). Recognised risk factors are represented by age, time from transplantation, female sex and smoking history $(46,47)$.

Generally, TCC treatment does not differ from normal clinical practice. Concerns about the use of intravesical BCG are related to the risk of sepsis and the possible reduced efficacy in immunocompromised patients. However, a recent study evaluating BCG use in RT patients with high-risk TCC did not report any side effect or a decrease in its efficacy. Further studies are needed to confirm these data (46). Another difference in treating TCC is radical cystectomy. Pelvic lymph node dissection is a mandatory step of the procedure that is not usually performed in RT patients on the graft side, mainly due to the fibrosis that surrounds the graft and the risk of vascular damages to the graft itself.

Prostate cancer (Pca) is the most frequent urologic malignancy in RT population with a two to five-fold greater risk than normal population (48). As far as immunosuppressive treatment alters host response to oncogenic stimuli, it is worldwide accepted that active surveillance is not a considerable option for RT patients who develop de-novo PCa. These patients are therefore treated with radical prostatectomy (RP) or radiation therapy. Concerning surgical strategy, no difference has been found between different approaches in terms of oncologic or functional outcomes: open retropubic, laparoscopic/robotic transperitoneal and transperineal RP (49). In a cohort study on retropubic RP, Lechevallier et al evidenced some surgical difficulties that might be encountered in RT recipients. First of all, caution is needed when placing the retractors in order to avoid ureteral or graft damage. Furthermore, it is almost always impossible to perform lymph node dissection on the side of the graft, as previously described for cystectomy. Finally, careful identification and dissection of the ureter of the graft is needed to avoid injuries (50).

\section{Lower urinary tract dysfunction related to $R T$}

Assessment of lower urinary tract function in future RT recipients is mandatory. This population can be divided into two groups: patients with a conserved diuresis and patients with disused bladders due to oliguria or complete anuria. The former needs to be evaluated with standard LUTS questionnaires, uroflowmetry and ultrasound with assessment of post-void residual volume, in order to rule out any bladder outlet obstruction or other less frequent conditions that could lead to graft damage (51). The latter needs careful evaluation because of an increased risk of developing filling phase LUTS after RT. Progressive reduction in bladder capacity and compliance is normally found in patients with ESRD due to an oliguric and then a progressively anuric state. Profound anatomic changes occur 
in disused bladder that leads to the development of a small and relatively poorly compliant bladder wall. In a comparative study, Chun et al analysed a population of 340 patients with ESRD demonstrating a linear and progressive relation between total dialysis years and both bladder capacity and compliance (52). Reduced bladder capacity and compliance may be responsible for the development of posttransplant LUTS, high-pressure bladder contraction and possibly graft damage. Careful evaluation of bladder function with urodynamic exam is therefore advisable before RT. The same authors showed that patients with bladder capacity inferior to $100 \mathrm{ml}$ had a higher risk of developing LUTS because bladder function most likely will not recover completely. Lefrancois et al (53), on the contrary, demonstrated that the majority of patients recover bladder capacity, contractility and function after RT. These findings were confirmed by Serrano et al, who performed urodynamic examination in previously anuric patients and demonstrated that bladder capacity reached normal values (300 $\mathrm{ml}$ ) after RT even in patients with a bladder capacity inferior to $100 \mathrm{ml}$ before RT (54). Other authors confirmed a progressive improvement of LUTS even at 6 years after RT (55). These findings question the need to perform a bladder augmentation before RT with the aim of obtaining a low bladder filling pressure and an adequate cistometric capacity. Morales et al evaluated the possibility of performing RT in patients with augmented bladder, showing that urinary tract infections (UTIs) due to excessive postvoid residue represented the principal complication. They concluded that RT in an augmented bladder is feasible both before and after RT, but there might be the need of a period of clean intermittent catheterisation to minimise the risk of UTIs (56).

\section{Graft urolithiasis}

Urinary stones in RT patients are a rare complication, with a posttransplant incidence inferior to $2 \%$ (57-59). Only case reports and small series ( $<35$ patients) described this event and its management. Renal stones may also be found already in the graft at procurement (so-called 'donor-gifted'). Asymptomatic renal stones were found in $19(5 \%)$ cases out of 377 potential living donors evaluated with CT scan by Olsburgh et al (60) and do not represent contraindication to RT but lead to a potential risk of severe postoperative complications. Treatment is indicated and most recent studies support ex-vivo ureterorenoscopy. Schade et al described 18 cases treated on bench by direct basket extraction or laser lithotripsy; all the recipients were stone-free at long-term follow-up (61). Similar results were reported by other studies, without any intra or postoperative complication, also in case of multiple stones $(60,62)$.

Post-transplant lithiasis can be found occasionally during follow-up. In case of ureteral migration, clinical presentation can be different as compared with general population: patients may report no pain because of graft denervations (57) and may present with urinary infections, haematuria and graft function impairment $(57,59)$. In other cases, clinical presentation may be dramatic with acute renal injury and sepsis (63), requiring immediate nephrostomy $(63,64)$. Elective treatments consist in conservative management, extracorporeal shockwave lithotripsy (ESWL), ureteroscopy, percutaneous nephrolithotomy and open surgery. Stones smaller than $4 \mathrm{~mm}$ can be safely managed by close surveillance alone, as they tend to remain stable or pass spontaneously without complications (65). ESWL is feasible in RT patients, even if stone targeting can be difficult due to the overlying bony pelvis. Prone position can counter this disadvantage. Challacombe et al successfully performed 13 ESWLs in a prone position (66), while in other series, a success rate more than $70 \%$ was reported without any complication $(57,64,67)$. Cassini et al concluded that ESWL could be safely performed in case of stones less than $15 \mathrm{~mm}$, while other treatments may be considered in case of failure (57). Ureteroscopy is also effective for stones less than $15 \mathrm{~mm}$, with direct basket extraction or Holmium laser lithotripsy. Both anterograde and retrograde approaches have been described (68). Retrograde ureteroscopy can be challenging due to the location and the mobility of reimplanted ureteral orifice. Most studies reported success rates of $60-80 \%(58,65,69)$. Hyams et al described seven successful retrograde ureteroscopy and recommended the use of a Kumpe catheter to facilitate the access to ureteral orifice (68). In case of stones larger than $15-20 \mathrm{~mm}, \mathrm{PCNL}$ is the non-surgical treatment with the highest stone-free rate (66). Krambeck et al presented one of the largest series of PCNL in RT patients, using a standard technique and dilating the existing nephrosotmy tract with Amplatz fascial dilators till 28Fr. Stone-free rate was $76 \%$, but after a second procedure, all patients became stone-free (70). Mini-percutaneous nephrolithotomy using a 8.5/11.5 F nephroscope was successfully described by He in 2007 in seven patients (71). Open surgery is still a valid option in most complex cases, especially when stones coexist with ureteral strictures, or after failure of minimally invasive procedures. Stone surgery in RT patients is challenging due to the high risk of vascular damage and systemic complications (63). In the largest series of renal graft stones reported by Verrier et al, eight out of 31 patients required open surgery to remove the stone and correct a concomitant ureteral stricture (65).

\section{Andrological dysfunctions related to $R T$}

End-stage renal disease affects patients' sexual and reproductive functions. As a matter of fact, erectile dysfunction (ED), loss of libido and infertility are frequently reported. Even if part of these problems can be restored after RT, sexual and reproductive troubles are common complaints in these patients (72-74). Thus urologists dealing with RT have to be familiar with diagnosis and treatment of andrological complaints.

\section{Sexual function}

Sexual function is a main aspect in everyday life of men. It has been widely demonstrated that an impairment in sexual function significantly leads to a decrease in the quality of life, and the same has been confirmed both in ESRD patients and $\mathrm{RT}$ recipients. Therefore, an adequate sexual function represents an important aspect and needs to be perceived in RT patients $(75,76)$. ESRD is frequently associated with sexual dysfunction and mainly with ED. Several factors have been considered as a risk factor to ED such as hormonal alteration, side effects of drugs, vascular interference or concomitant pathology such as diabetes mellitus and hypertension $(77,78)$. $\mathrm{RT}$ role in restoring a normal sexual function is still controversial and only few studies have clearly underlined the beneficial effects of RT on the erectile function (79-82). 
The prevalence of ED remains elevated even after transplantation (83-85). Sparse studies have revealed the possible negative effect of the graft arterial anastomosis on the arterial inflow of the penis, both in case of internal and external iliac anastomosis. Even if a strict connection between haemodynamic changes and RT has been well demonstrated, the direct relation with ED needs to be confirmed in prospective, randomised controlled studies $(86,87)$. RT recipients, indeed, often have other comorbidities, which might affect erectile function and represent a disturbing confounder in the relationship between RT and ED.

In case of ED, after a standard hormonal screening, RT recipients can be safely treated with Phosfodiesterase-5 inhibitors (PDE5-I) with excellent results in terms of erectile function recovery and low rate of adverse effect according to EAU guidelines $(88,89)$. In selected patients refractory to medical treatment, a penile prosthesis implantation can be proposed, even if a slightly higher rate of complication has to be considered (90). RT recipients, considering the previous pelvic surgery, can benefit from an ectopic reservoir placement between the transversalis fascia and the rectus muscle, in order to prevent possible complications related to a classical prevescical placement (91).

\section{Reproductive function}

It is widely accepted that ESRD is associated with impaired spermatogenesis and testicular damage. Main factors responsible are secondary to uremia in terms of hormonal, vascular and neuronal impairments $(92,93)$.

Moreover, as reported in the previous paragraph, the reproductive function can be affected as a consequence of sexual dysfunction. Even if RT represents the most effective solution to significantly improve the reproductive function, an increase in sperm count is reported in only half of RT patients. The factors, which negatively affect the possibility of recovering a normal reproductive function, are Folliculo-stimulating hormone (FSH) level before transplantation, a prolonged ESRD and previous dialysis (94). Probably, the main factor responsible affecting the reproductive function in transplanted patients is the use of immunosuppressive agents, which many studies suggest to be potentially gonadotoxic (95). Among the immunosuppressive agents used in RT recipients, few studies have underlined the potential gonadotoxic role of cyclosporine both in experimental models and in humans $(96,97)$, while sirolimus is well known to impair spermatogenesis. In the literature, few reports exist of azoospermic patients treated with sirolimus in which a complete restore of the spermatogenesis was reached after replacing sirolimus with tacrolimus (98).

However, if azoospermia is confirmed in two consecutive sperm analyses, a standard TeSE can be considered. No peculiar contraindications to TeSE are reported in RT recipients. Recently, the first case of a successful intracistoplasmatic injection of spermatozoa (ICSI) in an azoospermic and RT man has been described (99).

\section{Conclusion}

Renal transplantation is the treatment of choice for ESRD. Many surgical complications and clinical problems related to
$\mathrm{RT}$ represent a possible diagnostic and therapeutic challenge for the urologist.

Ureteral stenosis and urinary leakage represent the main surgical complications needing urologic care. The treatment of ureteral stenosis is mainly decided according to its severity. Surgery, especially ureteroneocistostomy, is the most effective treatment, but endourologic balloon dilatation or endoureterotomy represent the first option in case of short stenosis with the aim of reducing invasiveness. Surgery is therefore reserved to recurrent or severe stenosis and may involve the use of native excretory system. Urinary leakage is treated, according to its entity, with prolonged stenting and, if persistent or massive, with the same surgical interventions described for ureteral stenosis. AN is a surgical hazardous procedure that is needed when graft fails for whatever reason and that could be performed with either the intra or extracapsular way. Intracapsular AN seems to harbour less complication rate but might have the disadvantage of allosensitisation due to the fact that donor kidney capsule and ureter are left in situ.

Regarding de-novo urologic malignancies, RCC of native kidneys is the most frequent and it is best managed with radical nephrectomy irrespectively of neoplasm size. Nephron-sparing surgery is the treatment of choice for RCC of the graft with the aim of preserving the graft. TCC is relatively rare but seems to be more aggressive in immunosuppressed patients. For this reason, high-risk patients might probably benefit from an early aggressive radical treatment, such as radical cystectomy. Pca represents another possible therapeutic challenge mainly due to possible surgical difficulties. Active surveillance is usually not considered an option for RT recipients. Different surgical approaches to RP are considered effective. Transperineal RP may be used to reduce the risk of graft lesion, but it does not allow performing lymph node dissection.

$\mathrm{RT}$ recipients are at an increased risk of developing postRT LUTS due to reduced bladder capacity and contractility disorders. After RT, bladder retraining leads to the progressive recovery of its function and there are evidences that even after more than 6 months, LUTS may improve. In more severe cases, bladder augmentation before or after RT may be performed with acceptable long-term results.

Graft lithiasis is a rare RT complication. All treatment options, including SWL, ureterorenoscopy and PCNL, have high success rates and are chosen according to stone size and site. It must be taken into account that the lack of graft innervation can make renal colic totally asymptomatic in RT patients with urinary stones and acute renal insufficiency can be the first manifestation.

Sexual dysfunction is common in RT patients due to ESRD first and immunosuppressive treatment afterwards. Initial treatment with PDE5 inhibitors and, in case of failure, prosthesis implant represent the standards of care. According to fertility, azoospermia mainly due to immunosuppressive treatment has been reported. TeSE and ICSI proved to have promising results in these cases.

\section{Disclosures}

Financial support: The authors have no financial disclosures to make. Conflict of interest: The authors have no conflict of interest. 


\section{References}

1. Andrés A. Cancer incidence after immunosuppressive treatment following kidney transplantation. Crit Rev Oncol Hematol. 2005;56(1):71-85.

2. Phyllips B, Ball C, Sackett D. Levels of evidence and grades of recommendation. Oxford Centre for Evidence based Medicine web site http://www.cebm.net/index.aspx?o=1025 Accessed March 15, 2009.

3. Zagdoun E, Ficheux M, Lobbedez $\mathrm{T}$, et al. Complicated lymphoceles after kidney transplantation. Transplant Proc. 2010; 42(10):4322-4325.

4. Shoskes DA, Hanbury D, Cranston D, Morris PJ. Urological complications in 1,000 consecutive renal transplant recipients. J Urol. 1995;153(1):18-21.

5. Karam G, Hétet JF, Maillet F, et al. Late ureteral stenosis following renal transplantation: risk factors and impact on patient and graft survival. Am J Transplant. 2006;6(2):352-356.

6. van Aalderen MC, Heutinck KM, Huisman C, ten Berge IJM. BK virus infection in transplant recipients: clinical manifestations, treatment options and the immune response. Netherlands J Med. 2012;70:172-183.

7. Juaneda B, Alcaraz A, Bujons A, et al. Endourological management is better in early-onset ureteral stenosis in kidney transplantation. Transplant Proc. 2005;37(9):3825-3827.

8. Aytekin C, Boyvat F, Harman A, Ozyer U, Colak T, Haberal M. Percutaneous therapy of ureteral obstructions and leak after renal transplantation: long-term results. Cardiovasc Intervent Radiol. 2007;30(6):1178-1184.

9. Li Marzi V, Filocamo MT, Dattolo E, et al. The treatment of fistulae and ureteral stenosis after kidney transplantation. Transplant Proc. 2005;37(6):2516-2517.

10. Kim JC, Banner MP, Ramchandani P, Grossman RA, Pollack HM. Balloon dilation of ureteral strictures after renal transplantation. Radiology. 1993;186(3):717-722.

11. Bachar GN, Mor E, Bartal G, Atar E, Goldberg N, Belenky A. Percutaneous balloon dilatation for the treatment of early and late ureteral strictures after renal transplantation: long-term follow-up. Cardiovasc Intervent Radiol. 2004;27(4):335-338.

12. Helfand BT, Newman JP, Mongiu AK, Modi P, Meeks JJ, Gonzalez $\mathrm{CM}$. Reconstruction of late-onset transplant ureteral stricture disease. BJU Int. 2011;107(6):982-987.

13. He B, Bremner A, Han Y. Classification of ureteral stenosis and associated strategy for treatment after kidney transplant. Exp Clin Transplant. 2013;11(2):122-127.

14. Kristo B, Phelan MW, Gritsch HA, Schulam PG. Treatment of renal transplant ureterovesical anastomotic strictures using antegrade balloon dilation with or without holmium:YAG laser endoureterotomy. Urology. 2003;62(5):831-834.

15. Gdor Y, Gabr AH, Faerber GJ, Wolf JS Jr. Holmium:yttriumaluminum-garnet laser endoureterotomy for the treatment of transplant kidney ureteral strictures. Transplantation. 2008;85(9): 1318-1321.

16. Zavos G, Pappas P, Karatzas $\mathrm{T}$, et al. Urological complications: analysis and management of 1525 consecutive renal transplantations. Transplant Proc. 2008;40(5):1386-1390.

17. Król R, Ziaja J, Chudek J, et al. Surgical treatment of urological complications after kidney transplantation. Transplant Proc. 2006;38(1):127-130.

18. Tahir W, Hakeem A, White A, Irving HC, Lloyd SN, Ahmad N. Extra-anatomic stent (EAS) as a salvage procedure for transplant ureteric stricture. Am J Transplant. 2014;14(8):1927-1930.

19. Davari HR, Yarmohammadi H, Malekhosseini SA, Salahi H, Bahador A, Salehipour M. Urological complications in 980 consecutive patients with renal transplantation. Int J Urol. 2006; 13(10):1271-1275.
20. Streeter EH, Little DM, Cranston DW, Morris PJ. The urological complications of renal transplantation: a series of $1535 \mathrm{pa}-$ tients. BJU Int. 2002;90(7):627-634.

21. El-Mekresh M, Osman Y, Ali-El-Dein B, El-Diasty T, Ghoneim MA. Urological complications after living-donor renal transplantation. BJU Int. 2001;87(4):295-306.

22. Campbell SC, Streem SB, Zelch M, Hodge E, Novick AC. Percutaneous management of transplant ureteral fistulas: patient selection and long-term results. J Urol. 1993;150(4):1115-1117.

23. Alcaraz A, Bujons A, Pascual $X$, et al. Percutaneous management of transplant ureteral fistulae is feasible in selected cases. Transplant Proc. 2005;37(5):2111-2114.

24. Mazzucchi E, Souza GL, Hisano M, et al. Primary reconstruction is a good option in the treatment of urinary fistula after kidney transplantation. Int Braz J Urol. 2006;32(4):398-403, discussion 403-404.

25. Dinckan A, Tekin A, Turkyilmaz S, et al. Early and late urological complications corrected surgically following renal transplantation. Transpl Int. 2007;20(8):702-707.

26. Baston C, Harza M, Preda A, et al. Comparative urologic complications of ureteroneocystostomy in kidney transplantation: transvesical Leadbetter-Politano versus extravesical Lich-Gregoir technique. Transplant Proc. 2014;46(1):176-179.

27. Ameer A, Aljiffry M, Jamal M, et al. Complications of ureterovesical anastomosis in adult renal transplantation: comparison of the Lich-Gregoire and the Taguchi techniques. Ann Transplant. 2011;16(3):82-87.

28. Pike TW, Pandanaboyana S, Hope-Johnson T, Hostert L, Ahmad $\mathrm{N}$. Ureteric reconstruction for the management of transplant ureteric stricture: a decade of experience from a single centre. Transpl Int. 2015;28(5):529-534.

29. Salomon L, Saporta F, Amsellem D, et al. Results of pyeloureterostomy after ureterovesical anastomosis complications in renal transplantation. Urology. 1999;53(5):908-912.

30. Schult M, Küster J, Kliem V, et al. Native pyeloureterostomy after kidney transplantation: experience in 48 cases. Transpl Int. 2000;13(5):340-343.

31. Mahdavi Zafarghandi R, Sheikhi Zh. Extensive ureteral stricture in renal transplant recipients: prevalence and impact on graft and patient survival. Int J Organ Transplant Med. 2013;4(4): 165-171.

32. Mazzucchi E, Nahas WC, Antonopoulos IM, Piovesan AC, lanhez LE, Arap S. Surgical complications of graft nephrectomy in the modern transplant era. J Urol. 2003;170(3): 734-737.

33. Johnston O, Rose C, Landsberg D, Gourlay WA, Gill JS. Nephrectomy after transplant failure: current practice and outcomes. Am J Transplant. 2007;7(8):1961-1967.

34. Touma NJ, Sener A, Caumartin Y, Warren J, Nguan CY, Luke PP. Extracapsular versus intracapsular allograft nephrectomy: impact on allosensitization and surgical outcomes. Can Urol Assoc J. 2011;5(1):49-52.

35. Stewart JH, Vajdic CM, van Leeuwen MT, et al. The pattern of excess cancer in dialysis and transplantation. Nephrol Dial Transplant. 2009;24(10):3225-3231.

36. Brunner FP, Landais P, Selwood NH; European Dialysis and Transplantation Association-European Renal Association. Malignancies after renal transplantation: the EDTA-ERA registry experience. Nephrol Dial Transplant. 1995;10(Suppl 1):74-80.

37. Mahony JF, Caterson RJ, Coulshed S, Stewart JH, Sheil AG. Twenty and 25 years survival after cadaveric renal transplantation. Transplant Proc. 1995;27(3):2154-2155.

38. Sheil AG. Patterns of malignancies following renal transplantation. Transplant Proc. 1999;31(1-2):1263-1265.

39. Bijol V, Mendez GP, Hurwitz S, Rennke HG, Nosé V. Evaluation of the nonneoplastic pathology in tumor nephrectomy speci- 
mens: predicting the risk of progressive renal failure. Am J Surg Pathol. 2006;30(5):575-584.

40. Melchior S, Franzaring L, Shardan A, et al. Urological de novo malignancy after kidney transplantation: a case for the urologist. J Urol. 2011;185(2):428-432.

41. Breda A, Luccarelli G, Rodriguez-Faba O, Guirado L, Facundo C, Bettocchi $C$ et al. Clinical and pathological outcomes of renal cell carcinoma (RCC) in native kidneys of patients with end-stage renal disease: a long term comparative retrospective study with RCC diagnosed in general population. World J Urol. 2015;33:1-7.

42. Penn I. Occurrence of cancers in immunosuppressed organ transplant recipients. Clin Transpl. 1998;0890-9016:147-158.

43. Aiello FB. Incidental carcinoma of native kidneys in dialyzed and renal transplant patients: do we need new guidelines? Transpl Int. 2015;28(7):790-792.

44. Yan L, Chen P, Chen EZ, Gu A, Jiang ZY. Risk of bladder cancer in renal transplant recipients: a meta-analysis. $\mathrm{Br} J$ Cancer. 2014;110(7):1871-1877.

45. Zhang B, Shen C, Han WK, Yu W. Comparison of clinicopathologic characteristics of urothelial carcinoma between patients after renal transplantation and on dialysis. Transplantation. 2014;98(5):552-556.

46. Prabharasuth D, Moses KA, Bernstein M, Dalbagni G, Herr HW. Management of bladder cancer after renal transplantation. Urology. 2013;81(4):813-819.

47. Wu MJ, Lian JD, Yang CR, Cheng $\mathrm{CH}$, Chen $\mathrm{CH}$, Lee WC et al. High cumulative incidence of Urinary tract transitional cell carcinoma after kidney transplantation in Taiwan;

48. Kasiske BL, Snyder JJ, Gilbertson DT, et al. Cancer after kidney transplantation in the United States. Am J Transplant. 2004; 4:905-913.

49. Kleinclauss FM, Neuzillet $Y$, Tillou $X$, et al; Renal Transplantation Committee of French Urological Association. Morbidity of retropubic radical prostatectomy for prostate cancer in renal transplant recipients: multicenter study from Renal Transplantation Committee of French Urological Association. Urology. 2008; 72(6):1366-1370.

50. Kinahan TJ, Mc Loughlin MG, Manson AD. Radical prostatectomy for localized prostatic carcinoma in the renal transplant patient. J Urol. 1991;146(1):104-107.

51. Karam G, Giessing M. Bladder dysfunction following renal transplantation is it predictable? Transplant Proc. 2011;43(1): 387-390.

52. Chun JM, Jung GO, Park JB, et al. Renal transplantation in patients with a small bladder. Transplant Proc. 2008;40(7): 2333-2335.

53. Martin X, Aboutaieb R, Soliman S, el Essawy A, Dawahra M, Lefrancois $\mathrm{N}$. The use of long-term defunctionalized bladder in renal transplantation: is it safe? Eur Urol. 1999;36(5):450-453.

54. Serrano DP, Flechner SM, Modlin CS, Wyner LM, Novick AC. Transplantation into the long-term defunctionalized bladder. J Urol. 1996;156(3):885-888.

55. Zermann DH, Janitzky A, Höhne M, Schubert J. Frequency and nocturia after successful renal transplantation: a normal situation? BJU Int. 2006;97(3):555-558.

56. Blanco M, Medina J, Pamplona M, Miranda N, Gonzalez E, Aguirre JF et al. Outcome of renal transplantation in adult patients with augmented bladders. Transp Proc. 2009;41(6):2382-2384.

57. Ferreira Cassini M, Cologna AJ, Ferreira Andrade M, et al. Lithiasis in 1,313 kidney transplants: incidence, diagnosis, and management. Transplant Proc. 2012;44(8):2373-2375.

58. Cicerello E, Merlo F, Mangano M, Cova G, Maccatrozzo L. Urolithiasis in renal transplantation: diagnosis and management. Arch Ital Urol Androl. 2014;86(4):257-260.

59. Mamarelis G, Vernadakis S, Moris D, et al. Lithiasis of the renal allograft, a rare urological complication following renal trans- plantation: a single-center experience of 2,045 renal transplantations. Transplant Proc. 2014;46(9):3203-3205.

60. Olsburgh J, Thomas K, Wong K, et al. Incidental renal stones in potential live kidney donors: prevalence, assessment and donation including the role of ex vivo ureteroscopy. BJU Int. 2012.

61. Schade GR, Wolf JS Jr, Faerber GJ. Ex-vivo ureteroscopy at the time of live donor nephrectomy. J Endourol. 2011;25(9): 1405-1409.

62. Rashid MG, Konnak JW, Wolf JS Jr, et al. Ex vivo ureteroscopic treatment of calculi in donor kidneys at renal transplantation. J Urol. 2004;171(1):58-60.

63. Wong KA, Olsburgh J. Management of stones in renal transplant. Curr Opin Urol. 2013;23(2):175-179.

64. Klingler HC, Kramer G, Lodde M, Marberger M. Urolithiasis in allograft kidneys. Urology. 2002;59(3):344-348.

65. Verrier C, Bessede T, Hajj P, Aoubid L, Eschwege P, Benoit G. Decrease in and management of urolithiasis after kidney transplantation. J Urol. 2012;187(5):1651-1655.

66. Challacombe B, Dasgupta P, Tiptaft R, et al. Multimodal management of urolithiasis in renal transplantation. BJU Int. 2005; 96(3):385-389.

67. Li SD, Wang QT, Chen WG. Treatment of urinary lithiasis following kidney transplantation with extracorporeal shock-wave lithotripsy. Chin Med J (Engl). 2011;124(9):1431-1434.

68. Hyams E, Marien T, Bruhn A, et al. Ureteroscopy for transplant lithiasis. J Endourol. 2012;26(7):819-822.

69. Basiri A, Nikoobakht MR, Simforoosh N, Hosseini Moghaddam SM. Ureteroscopic management of urological complications after renal transplantation. Scand J Urol Nephrol. 2006;40(1): 53-56.

70. Krambeck AE, Leroy AJ, Patterson DE, Gettman MT. Percutaneous nephrolithotomy success in the transplant kidney. J Urol. 2008;180(6):2545-2549.

71. He Z, Li X, Chen L, Zeng G, Yuan J. Minimally invasive percutaneous nephrolithotomy for upper urinary tract calculi in transplanted kidneys. BJU Int. 2007;99(6):1467-1471.

72. Diemont WL, Vruggink PA, Meuleman EJ, Doesburg WH, Lemmens WA, Berden JH. Sexual dysfunction after renal replacement therapy. Am J Kidney Dis. 2000;35(5):845-851.

73. Rosas SE, Joffe M, Franklin E, et al. Association of decreased quality of life and erectile dysfunction in hemodialysis patients. Kidney Int. 2003;64(1):232-238.

74. Holdsworth SR, de Kretser DM, Atkins RC. A comparison of hemodialysis and transplantation in reversing the uremic disturbance of male reproductive function. Clin Nephrol. 1978; 10(4):146-150.

75. Hricik DE, Halbert RJ, Barr ML, et al. Life satisfaction in renal transplant recipients: preliminary results from the transplant learning center. Am J Kidney Dis. 2001;38(3):580-587.

76. Matas AJ, Halbert RJ, Barr ML, et al. Life satisfaction and adverse effects in renal transplant recipients: a longitudinal analysis. Clin Transplant. 2002;16(2):113-121.

77. Melman A, Gingel JC. The epidemiology and pathophysiology of erectile dysfunction. J Urol. 1999;161:5e11.

78. Toorians AW, Janssen E, Laan E, et al. Chronic renal failure and sexual functioning: clinical status versus objectively assessed sexual response. Nephrol Dial Transplant. 1997;12:2654e2663.

79. Hegarty PK, Olsburgh J. Renal replacement and male sexuality. Transplant Proc. 2012;44(6):1804-1805.

80. Mehrsai A, Mousavi S, Nikoobakht M, Khanlarpoor T, Shekarpour L, Pourmand G. Improvement of erectile dysfunction after kidney transplantation: the role of the associated factors. Urol J. 2006;3(4):240-244.

81. Tavallaii SA, Mirzamani M, Heshmatzade Behzadi A, et al. Sexual function: a comparison between male renal transplant recipients and hemodialysis patients. J Sex Med. 2009;6(1):142-148. 
82. Nassir A, Motavalli SM, Aghdam B. Sexual function in male patients undergoing treatment for renal failure: a prospective view. J Sex Med. 2009;6(12):3407-3414.

83. Malavaud B, Rostaing L, Rischmann P, Sarramon JP, Durand D. High prevalence of erectile dysfunction after renal transplantation. Transplantation. 2000;69(10):2121-2124.

84. Mirone V, Longo N, Fusco F, et al. Renal transplantation does not improve erectile function in hemodialysed patients. Eur Urol. 2009;56(6):1047-1053.

85. Espinoza R, Gracida C, Cancino J, Ibarra A. Prevalence of erectile dysfunction in kidney transplant recipients. Transplant Proc. 2006;38(3):916-917.

86. El-Bahnasawy MS, El-Assmy A, Dawood A, et al. Effect of the use of internal iliac artery for renal transplantation on penile vascularity and erectile function: a prospective study. J Urol. 2004;172(6 Pt 1):2335-2339.

87. Gontero P, Oderda M, Filippini C, et al. Does kidney transplantation onto the external iliac artery affect the haemodynamic parameters of the cavernosal arteries? Asian J Androl. 2012; 14(4):621-625.

88. Lasaponara F, Sedigh O, Pasquale G, et al. Phosphodiesterase type 5 inhibitor treatment for erectile dysfunction in patients with end-stage renal disease receiving dialysis or after renal transplantation. J Sex Med. 2013;10(11):2798-2814.

89. Hatzimouratidis K, Amar E, Eardley I, et al; European Association of Urology. Guidelines on male sexual dysfunction: erectile dysfunction and premature ejaculation. Eur Urol. 2010;57(5): 804-814.

90. Cuellar DC, Sklar GN. Penile prosthesis in the organ transplant recipient. Urology. 2001;57(1):138-141.

91. Stember DS, Garber BB, Perito PE. Outcomes of abdominal wall reservoir placement in inflatable penile prosthesis implanta- tion: a safe and efficacious alternative to the space of Retzius. J Sex Med. 2014;11(2):605-612.

92. Toorians AW, Janssen E, Laan E, et al. Chronic renal failure and sexual functioning: clinical status versus objectively assessed sexual response. Nephrol Dial Transplant. 1997;12(12):2654-2663.

93. Holdsworth S, Atkins R, de Kretser D. The pituitary-testicular axis in men with chronic renal failure. N Engl J Med. 1977;296: $1245-1249$.

94. De Celis R, Pedrón-Nuevo N. Male fertility of kidney transplant patients with one to ten years of evolution using a conventional immunosuppressive regimen. Arch Androl. 1999;42(1): 9-20.

95. Lessan-Pezeshki M, Ghazizadeh S. Sexual and reproductive function in end-stage renal disease and effect of kidney transplantation. Asian J Androl. 2008;10(3):441-446.

96. Seethalakshmi L, Diamond DA, Malhotra RK, Mazanitis SG, Kumar S, Menon M. Cyclosporine-induced testicular dysfunction: a separation of the nephrotoxic component and an assessment of a 60-day recovery period. Transplant Proc. 1988;20(3) (Suppl 3):1005-1010.

97. Seethalakshmi L, Flores C, Carboni AA, Bala R, Diamond DA, Menon M. Cyclosporine: its effects on testicular function and fertility in the prepubertal rat. J Androl. 1990;11(1): 17-24.

98. Skrzypek J, Krause W. Azoospermia in a renal transplant recipient during sirolimus (rapamycin) treatment. Andrologia. 2007;39(5):198-199.

99. Balmori C, Guillén A, Montans J, Bronet F, García-Velasco JA. Successful ICSI in an azoospermic and kidney transplant man with type 1 primary hyperoxaluria and first histopathological testicular findings described in the literature. Andrologia. 2015;47(1):109-111. 